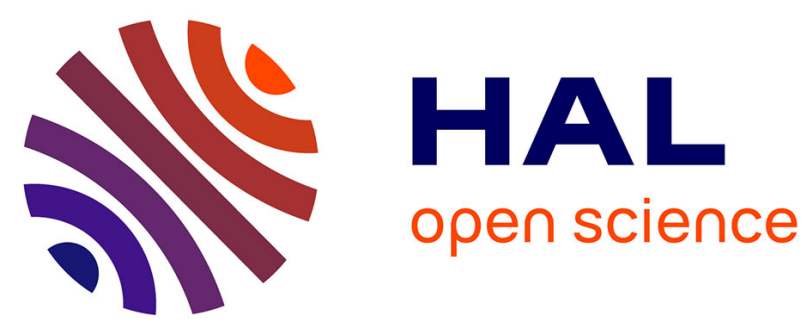

\title{
Gemcitabine and Oxaliplatin, but Not Sorafenib or Paclitaxel, Have a Synergistic Effect with Yttrium-90 in Reducing Hepatocellular Carcinoma and Cholangiocarcinoma Cell Line Viability.
}

Julien Edeline, Cédric Coulouarn, Laurence Crouzet, Marc Pracht, Nicolas

Lepareur, Bruno Clément, Etienne Garin

\section{To cite this version:}

Julien Edeline, Cédric Coulouarn, Laurence Crouzet, Marc Pracht, Nicolas Lepareur, et al.. Gemcitabine and Oxaliplatin, but Not Sorafenib or Paclitaxel, Have a Synergistic Effect with Yttrium-90 in Reducing Hepatocellular Carcinoma and Cholangiocarcinoma Cell Line Viability.. JVIR: Journal of Vascular and Interventional Radiology, 2015, 26 (12), pp.1874-1878.e2. 10.1016/j.jvir.2015.06.032 . hal-01237102

HAL Id: hal-01237102

https://hal-univ-rennes1.archives-ouvertes.fr/hal-01237102

Submitted on 31 May 2016

HAL is a multi-disciplinary open access archive for the deposit and dissemination of scientific research documents, whether they are published or not. The documents may come from teaching and research institutions in France or abroad, or from public or private research centers.
L'archive ouverte pluridisciplinaire HAL, est destinée au dépôt et à la diffusion de documents scientifiques de niveau recherche, publiés ou non, émanant des établissements d'enseignement et de recherche français ou étrangers, des laboratoires publics ou privés. 


\section{Gemcitabine and Oxaliplatin, but Not Sorafenib or Paclitaxel, Have a Synergistic Effect with Yttrium-90 in Reducing Hepatocellular Carcinoma and Cholangiocarcinoma Cell Line Viability}

Julien Edeline, MDa, c, , Cédric Coulouarn, PhDc, Laurence Crouzet, MDa, c, Marc Pracht, MDa, Nicolas Lepareur, PhDb, c, Bruno Clément, PhDc, Etienne Garin, $\mathrm{MD}, \mathrm{PhDb}, \mathrm{C}$

a Department of Medical Oncology, Centre Eugène Marquis, Av de la bataille Flandres Dunkerque, Rennes 35043, France

b Department of Nuclear Medicine, Centre Eugène Marquis, Av de la bataille Flandres Dunkerque, Rennes 35043, France

c Inserm UMR991, Rennes, France

\section{Abstract}

Synergy between Yttrium-90 $\left({ }^{90} \mathrm{Y}\right)$ and drugs was investigated. Viability of HepaRG (hepatocellular carcinoma) and HuCCT1 (cholangiocarcinoma) cells was studied through a tetrazolium dye reduction (MTT) assay. A combination index $(\mathrm{Cl})$ was calculated, $\mathrm{Cl}<1$ denoting synergy and $\mathrm{Cl}>1$ antagonism. In HepaRG, gemcitabine showed synergy with ${ }^{90} \mathrm{Y}(\mathrm{Cl}=0.70[0.65-0.75])$, while oxaliplatin $(\mathrm{Cl}=1.15$ [1.081.21] $)$, paclitaxel $(\mathrm{Cl}=1.26[1.15-1.37])$ and sorafenib $(\mathrm{Cl}=1.77[1.65-1.89])$ showed antagonism. In HuCCT1, gemcitabine $(\mathrm{Cl}=0.54$ [0.50-0.58]) and oxaliplatin $(\mathrm{Cl}=0.86$ [0.82-0.90]) showed synergy with ${ }^{90} \mathrm{Y}$, while paclitaxel $(\mathrm{Cl}=1.18$ [1.09-1.27]) and sorafenib $(\mathrm{Cl}=1.21[1.12-1.30])$ showed antagonism. These results suggest that gemcitabine and oxaliplatin should be tested in combination with ${ }^{90}$ Yradioembolization in liver cancer. 
Keywords: Hepatocellular carcinoma; cholangiocarcinoma; Yttrium-90; SIRT; chemotherapy

\section{Introduction:}

Yttrium-90 ( ${ }^{90}$ Y)-radioembolization, or Selective Internal Radiation Therapy (SIRT) is an emerging treatment modality for liver malignancies. It showed similar results as transarterial chemoembolization in intermediate hepatocellular carcinoma (HCC) (1). Some series also report promising activity in intrahepatic cholangiocarcinoma (ICC) (2). SIRT is used as monotherapy in primary liver cancer. However, it might be hypothesized that combination with systemic treatments may be beneficial by treating micrometastases, but also potentially by enhancing efficiency of SIRT through a synergistic effect on the primary tumor. However, these potential synergy might also lead to a risk of increased toxicity. SIRT is now being tested in metastatic colorectal cancer with concurrent chemotherapy, rather than alone (e.g. in the EPOCH trial, clinicaltrials.gov identifier NCT01483027, the FoxfireGlobal trial, NCT01721954, and the SIRFLOX trial, NCT00724503).

In advanced HCC, the only validated systemic agent is sorafenib, a tyrosine-kinase inhibitor targeting VEGFR, RAF and other kinases. However, systemic chemotherapy could be used with some evidence of efficacy. The combination of gemcitabine and oxaliplatin showed some activity in advanced HCC (3). In advanced ICC, the standard systemic treatment consists of a combination of gemcitabine and a platinum compound, but response rates are lower than 25\% (4). Gemcitabine, oxaliplatin and paclitaxel have been shown to exhibit a synergistic effect with external beam radiotherapy, and some clinical applications exist, notably in pancreatic cancer (5). 
Paclitaxel is used as a radiosensitizing agent for lung cancer, and could thus be tested as potential radiosensitizing agent for primary liver cancers (6).

Sorafenib, gemcitabine, oxaliplatin and paclitaxel would thus be relevant drugs to test in combination with SIRT for primary liver malignancies. To our knowledge, no data were reported as regard to synergy between antineoplastic drugs and ${ }^{1} \mathrm{Y}$. The purpose of the study was thus to identify potential synergy between antineoplastic drugs and ${ }^{90} \mathrm{Y}$ in primary liver cancer cell lines.

\section{Materials and methods}

Cell lines

HepaRG was used as a hepatocarcinoma cell line, and HuCCT1 as a cholangiocarcinoma cell line $(7,8)$. HepaRG cells were grown in William's $E$ medium supplemented with $10 \%$ fetal bovine serum (FBS), $100 \mathrm{U} / \mathrm{mL}$ penicillin, $100 \mu \mathrm{g} / \mathrm{mL}$ streptomycin, $5 \mu \mathrm{g} / \mathrm{mL}$ insulin, and $50 \mu \mathrm{M}$ hydrocortisone hemisuccinate. HuCCT1 cells were provided by the RIKEN BioResource Centre, Japan, and were grown in RPMI 1640 medium supplemented with $10 \%$ FBS, $100 \mathrm{U} / \mathrm{mL}$ penicillin, $100 \mu \mathrm{g} / \mathrm{mL}$

${ }^{1} \mathrm{Y}$ was provided with an activity of $740 \mathrm{MBq}(20 \mathrm{mCi})$ in sterile condition as Yttrium chloride and diluted in the cell culture medium to reach the selected activity, measured using a Capintec CRC-127R well-counter. Sorafenib was diluted in dimethylsulfoxyde at $10 \mathrm{nM}$. Gemcitabine was diluted in $0.9 \%$ Sodium Chloride at a stock concentration of $38 \mathrm{mg} / \mathrm{mL}$. Oxaliplatin was diluted in $5 \%$ glucose at a stock 
streptomycin and 2mM L-glutamine. HepG2 and Huh28 cells were also studied as confirmatory cell lines for hepatocarcinoma and cholangiocarcinoma, respectively.

\section{Treatments}

concentration of $5 \mathrm{mg} / \mathrm{mL}$. Paclitaxel was diluted in $0.9 \%$ Sodium Chloride at a stock concentration of $6 \mathrm{mg} / \mathrm{mL}$. Each drug was subsequently diluted in the cell culture medium.

\section{Cell viability assay}

Twenty-four hours after seeding, cells were treated with ${ }^{90} \mathrm{Y}$ and/or drugs for 72 hours. To measure cell viability, the 3-(4,5-dimethylthiazol-2-yl)2,5diphenyltetrazolium (MTT) assay was used. The reduction of MTT into formazan salts in mitochondria of viable cells produces a coloration that could be measured by spectrophotometry, the coloration being linearly proportionate to the number of viable cells (9). Percentages of cell viability assessed by the MTT assay were then plotted against drug concentrations and ${ }^{90} \mathrm{Y}$ activities to evaluate concentrations inducing a $20 \%$ to $50 \%$-reduction in cell viability, which was used to test in combination assays. This range of reduction of cell viability was chosen to be able to detect significant additivity or synergy: a higher reduction in cell viability in monotherapy would have led to insufficient viability in combination to distinguish synergy from additivity, and a lower reduction would have made difficult to detect any additivity. Every assay was performed in triplicate, and every experiment was repeated three times. 


\section{Combination index}

A combination index $(\mathrm{Cl})$ was calculated to identify additive or synergistic (supraadditive) effects. $\mathrm{Cl}$ is the ratio between the effect observed for the combination and the theoretical additive effect calculated (10). The theoretical additive effect (TAE) was calculated by multiplying the individual effect reported with each drug used separately. $\mathrm{Cl}$ equals to 1 denoted additivity, $<1$ denoted synergy and $>1$ denoted antagonism. Ninety-five percent confidence intervals were calculated to determine statistical significance.

\section{Results}

First, the effect on cell viability following each treatment was studied individually to select activities and concentrations suitable to identify additive or synergistic effects in combination assays (Table 1 and Figure E1). Higher activity for ${ }^{1} Y$ was used for HuCCT1 cells as compared with HepaRG cells because no inhibitory effect was seen

${ }^{1} \mathrm{Y}(\mathrm{Cl}=1.15[1.08-1.21])$, as was paclitaxel $(\mathrm{Cl}=1.26[1.15-1.37])$, and sorafenib $(\mathrm{Cl}=1.77$ [1.65-1.89]). Results regarding HuCCT1 cells are reported on Figure 2. There was a clear synergy between gemcitabine and ${ }^{90} \mathrm{Y}(\mathrm{Cl}=0.54[0.50-0.58])$, as well as between oxaliplatin and ${ }^{90} \mathrm{Y}(\mathrm{Cl}=0.86[0.82-0.90])$. However, there was an antagonist effect between paclitaxel and ${ }^{90} \mathrm{Y}(\mathrm{Cl}=1.18$ [1.09-1.27]), and between sorafenib and ${ }^{90} \mathrm{Y}(\mathrm{Cl}=1.21[1.12-1.30])$. Similar results were obtained using HepG2 and Huh28 cell lines (Figures E2 and E3). 
at $1.11 \mathrm{MBq}$ for HuCCT1 while an excessive inhibitory effect to properly assess additivity was seen at 3.7 MBq for HepaRG.

Then, the effects of the combination of ${ }^{90} \mathrm{Y}$ with the different drugs were evaluated in both cell lines. Results concerning HepaRG cells are reported on Figure 1. Gemcitabine had a clear synergistic effect when combined with ${ }^{90} \mathrm{Y}$, with a $\mathrm{Cl}=0.70$ [95\% confidence interval: $0.65-0.75]$. Oxaliplatin was antagonist when combined with Discussion

As most of the patients eventually progress following SIRT, with a median time to progression between 8 to 14 months in large HCC series (1), development of strategies to improve efficacy are warranted. Using systemic treatment in combination with SIRT for synergy is potentially such a strategy.

The results presented here showed a strong synergistic effect between gemcitabine and ${ }^{90} \mathrm{Y}$ in both cell lines. This is consistent with the known radiosensitizing effect of the drug (5). While synergy between oxaliplatin and ${ }^{90} Y$ was shown in the cholangiocarcinoma cell lines, it was not the case in the HCC cell lines. By contrast, paclitaxel and sorafenib showed antagonism with ${ }^{90} \mathrm{Y}$. However, the design of this in vitro study could not address whether the synergistic combinations could also increase liver toxicity.

These results provide first preclinical evidence to study the combination of gemcitabine and oxaliplatin with ${ }^{90} \mathrm{Y}$-SIRT in primary liver malignancies. Gemcitabine and 5-fluorouracile were previously studied in combination with low dose of external beam radiation (11), and cisplatin and 5-fluorouracile were shown to have synergistic effect with lodine-131 (12). With Rhenium-188, 5-fluorouracile had only a transient 
supra additive effect (13) and sorafenib showed evidence of synergy (14). All of these data suggest that systemic treatments may enhance efficacy of SIRT.

To date, sorafenib is the only drug tested in combination with SIRT in HCC. The rationale for such combination lies on proven activity of both treatment used as monotherapy, and on potential effects of SIRT on secretion of angiogenic factors

(15). However, the results of anti-angiogenic drugs in the tumoral vasculature may be difficult to predict, and little is known whether it would have a beneficial or a detrimental effect on tumoral uptake of microspheres. However, the results of the present study suggest that combination of sorafenib with ${ }^{90} \mathrm{Y}$ might have an antagonist effect on tumoral cell growth itself, but its design did not address the effect on angiogenesis.

This study has some limitations. The conclusions drawn would have been reinforced by replication in an in vivo model. It is difficult to correlate activity received in an in vitro model and activity received by the tumor in patients, but the activity received in this study are approximately 1000 times less than activity injected in an approximately 1000 times greater volume in clinics, so might probably be viewed as "in a clinical range". The study design did not address the question of angiogenesis, which is one of the mechanisms of action of sorafenib, and the interactions between SIRT, angiogenesis and hypoxia. The potential increase of toxicity could also not be studied in vitro.

In conclusion, this study supports the use of gemcitabine and oxaliplatin in combination with SIRT in HCC and ICC, but not the use of paclitaxel or sorafenib. Clinical trial of combination of gemcitabine-platinum compounds with SIRT are 
warranted on HCC and ICC, and a phase II study combining glass microsphere SIRT and gemcitabine-cisplatin in ICC is now recruiting patients (Misphec Study, NCT01912053).

\section{References}

1. Salem R, Lewandowski RJ, Kulik L, Wang E, Riaz A, Ryu RK, et al.

Radioembolization results in longer time-to-progression and reduced toxicity compared with chemoembolization in patients with hepatocellular carcinoma. Gastroenterology. 2011;140(2):497-507.e2.

2. Mouli S, Memon K, Baker T, Benson AB, Mulcahy MF, Gupta R, et al. Yttrium-90 Radioembolization for Intrahepatic Cholangiocarcinoma: Safety, Response, and Survival Analysis. J Vasc Interv Radiol. 2013;24(8):1227-34.

3. Zaanan A, Williet N, Hebbar M, Dabakuyo TS, Fartoux L, Mansourbakht T, et al. Gemcitabine plus oxaliplatin in advanced hepatocellular carcinoma: a large multicenter AGEO study. J Hepatol. 2013;58(1):81-8.

4. Valle J, Wasan H, Palmer DH, Cunningham D, Anthoney A, Maraveyas A, et al. Cisplatin plus gemcitabine versus gemcitabine for biliary tract cancer. N Engl $\mathrm{J}$ Med. 2010;362(14):1273-81.

5. Zhu C-P, Shi J, Chen Y-X, Xie W-F, Lin Y. Gemcitabine in the chemoradiotherapy for locally advanced pancreatic cancer: a meta-analysis. Radiother Oncol. 2011;99(2):108-13.

6. Bradley JD, Paulus R, Komaki R, Masters G, Blumenschein G, Schild S, et al. Standard-dose versus high-dose conformal radiotherapy with concurrent and consolidation carboplatin plus paclitaxel with or without cetuximab for patients 
with stage IIIA or IIIB non-small-cell lung cancer (RTOG 0617): a randomised, two-by-two factorial phase 3 study. Lancet Oncol. 2015;16(2):187-99.

7. Cuconati A, Mills C, Goddard C, Zhang X, Yu W, Guo H, et al. Suppression of AKT anti-apoptotic signaling by a novel drug candidate results in growth arrest and apoptosis of hepatocellular carcinoma cells. PloS One. 2013;8(1):e54595.

8. Iwahashi S, Ishibashi H, Utsunomiya T, Morine Y, Ochir TL, Hanaoka J, et al. Effect of histone deacetylase inhibitor in combination with 5-fluorouracil on pancreas cancer and cholangiocarcinoma cell lines. J Med Investig. $2011 ; 58(12): 106-9$.

9. Stoddart MJ. Cell viability assays: chapter 3: Estimation of Cell Number Based on Metabolic Activity: The MTT Reduction Assay. Methods Mol Biol Clifton NJ. $2011 ; 740: 13-9$.

10. Zhao L, Wientjes MG, Au JL-S. Evaluation of combination chemotherapy: integration of nonlinear regression, curve shift, isobologram, and combination index analyses. Clin Cancer Res. 2004;10(23):7994-8004.

11. Cuneo KC, Davis MA, Feng MU, Novelli PM, Ensminger WD, Lawrence TS. Lowdose rate radiosensitization of hepatocellular carcinoma in vitro and in patients. TransI Oncol. 2014;7(4):472-8.

12. Chenoufi N, Raoul J-L, Lescoat G, Brissot P, Bourguet P. In vitro demonstrationof synergy between radionuclide and chemotherapy. J Nucl Med. 1998;39(5):900-3. 
13. Lambert B, De Ridder L, De Vos F, Slegers G, de Gelder V, Van de Wiele C, etal. Assessment of supra-additive effects of cytotoxic drugs and low dose rate irradiation in an in vitro model for hepatocellular carcinoma. Can J Physiol Pharmacol. 2006;84(10):1021-8.

14. Pracht M, Edeline J, Lepareur N, Lenoir L, Ardisson V, Clement B, et al. In vitrodemonstration of synergy/additivity between (188)rhenium and sorafenib on hepatoma lines: preliminary results. Anticancer Res. 2013;33(9):3871-7.

15. Carpizo DR, Gensure RH, Yu X, Gendel VM, Greene SJ, Moore DF, et al. Pilotstudy of angiogenic response to yttrium-90 radioembolization with resin microspheres. J Vasc Interv Radiol. 2014;25(2):297-306.e1. 


\section{Figure legends}

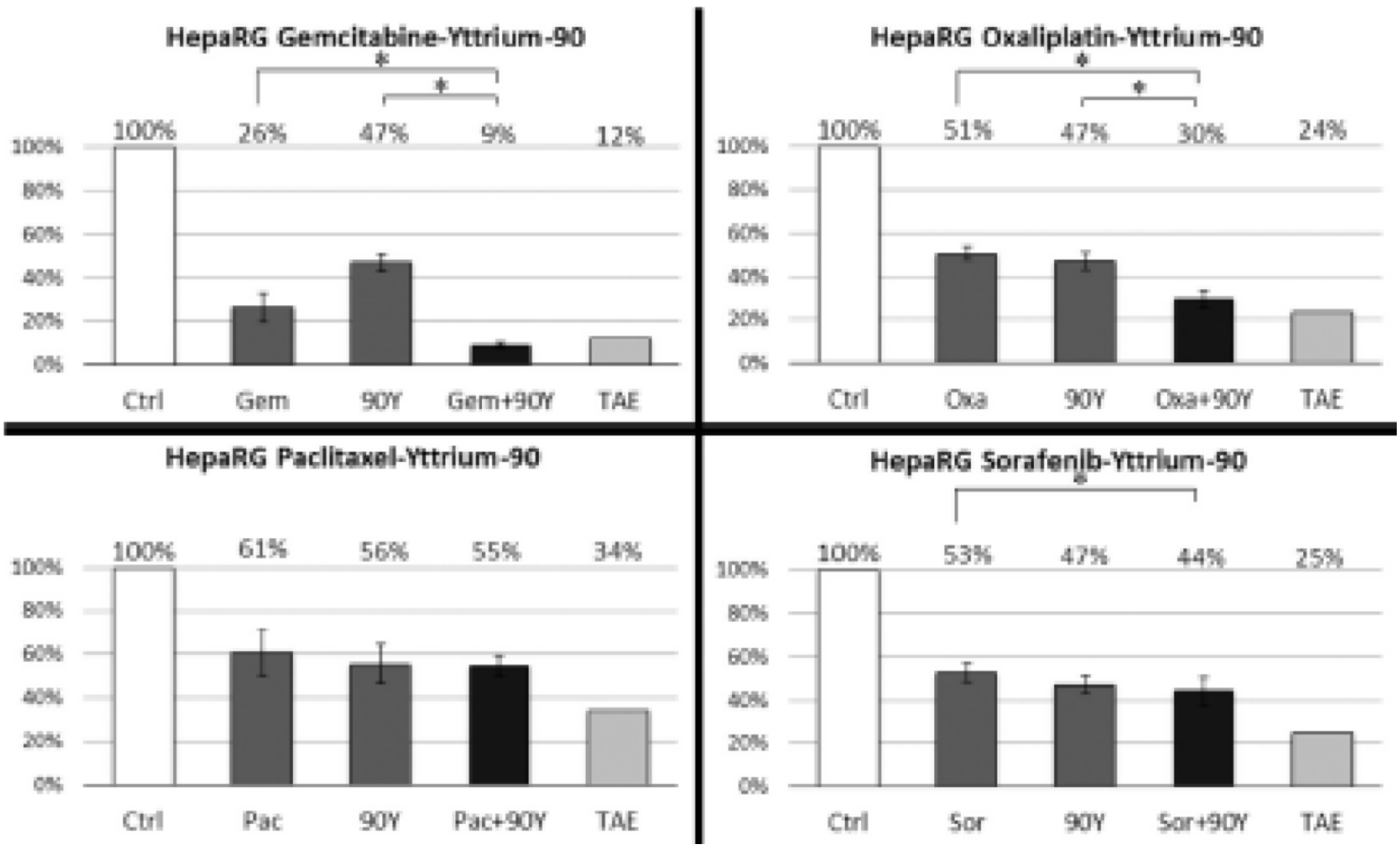

Figure 1: Cell viability following treatment of HepaRG cells with gemcitabine, oxaliplatin, paclitaxel or sorafenib alone or in combination with ${ }^{90}$ Y. Ctrl: Control; Gem: Gemcitabine; 90Y: Yttrium-90; Oxa: Oxaliplatin; Pac: Paclitaxel; Sor: Sorafenib; TAE: Theoretical Additive Effect. The TAE column is the calculated product of cell viability following the two individual treatments. It reflects the value corresponding to a Combination Index of 1 (perfect addition). Value of the control is based on normalization. ${ }^{*}$ denotes $p<0.05$. 


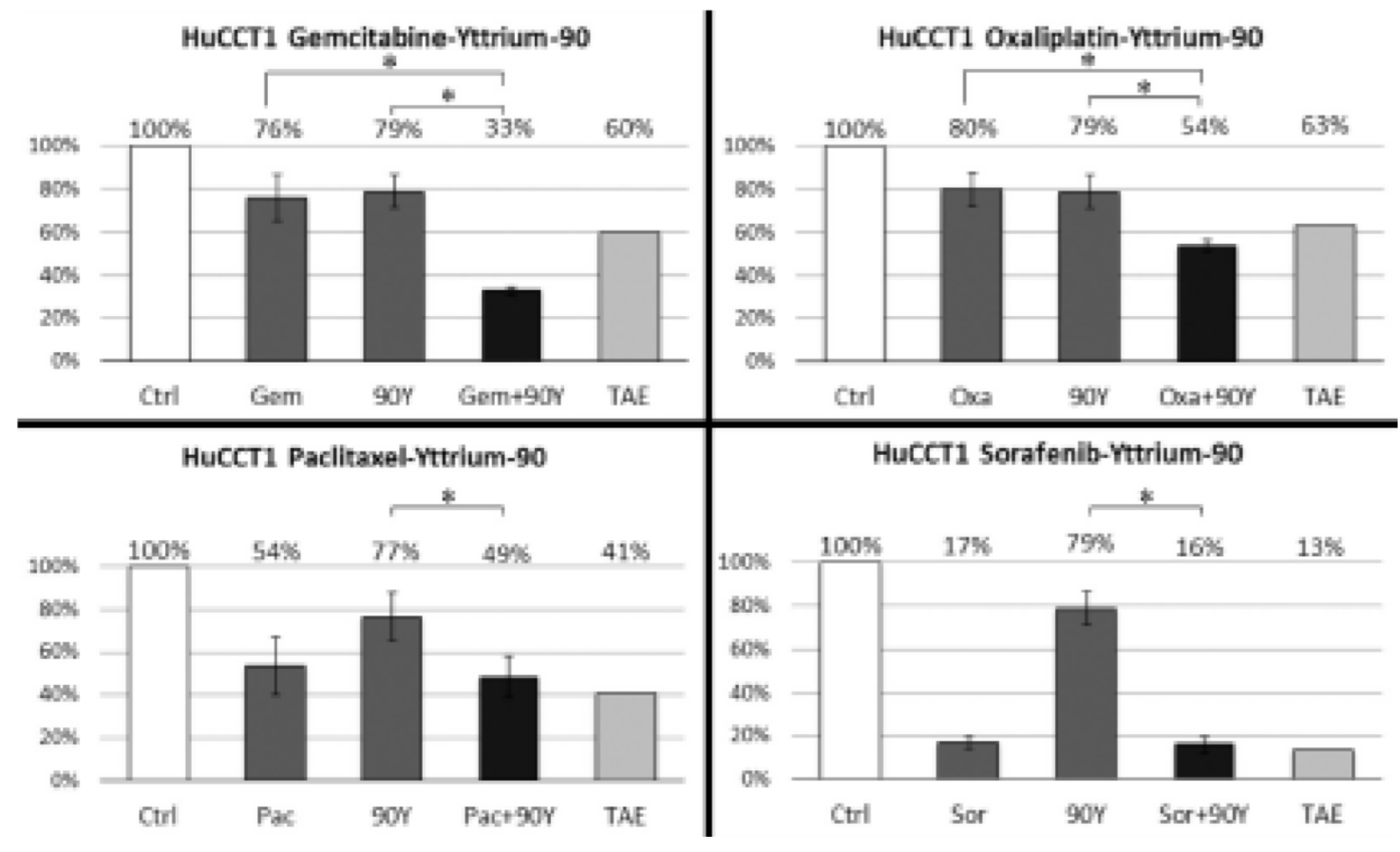

Figure 2: Cell viability following treatment of HuCCT1 cells with gemcitabine, oxaliplatin, paclitaxel or sorafenib alone or in combination with ${ }^{90} \mathrm{Y}$. Ctrl: Control; Gem: Gemcitabine; 90Y: Yttrium-90; Oxa: Oxaliplatin; Pac: Paclitaxel; Sor: Sorafenib; TAE: Theoretical Additive Effect. The TAE column is the calculated product of cell viability following the two individual treatments. It reflects the value corresponding to a Combination Index of 1 (perfect addition). Value of the control is based on normalization. ${ }^{*}$ denotes $p<0.05$.

Figure E1: Cell viability following treatments of HepaRG (upper line) and HuCCT1 (lower line) with ${ }^{90} \mathrm{Y}$, gemcitabine, oxaliplatin, paclitaxel and sorafenib monotherapy. Isobars represent $95 \%$ confidence intervals. These dose-response assessment were used to select the dose inducing 20 to $50 \%$-decrease of cell viability, to test in the combination experiments. 
Figure E2: Cell viability following treatment of HepG2 cells with gemcitabine, oxaliplatin, paclitaxel or sorafenib alone or in combination with ${ }^{90} \mathrm{Y}$. Ctrl: Control; Gem: Gemcitabine; 90Y: Yttrium-90; Oxa: Oxaliplatin; Pac: Paclitaxel; Sor: Sorafenib; TAE: Theoretical Additive Effect. The TAE column is the calculated product of cell viability following the two individual treatments. It reflects the value corresponding to a Combination Index of 1 (perfect addition). Value of the control is based on normalization. ${ }^{*}$ denotes $p<0.05$.

Figure E3: Cell viability following treatment of Huh28 cells with gemcitabine, oxaliplatin, paclitaxel or sorafenib alone or in combination with ${ }^{90} \mathrm{Y}$. Ctrl: Control; Gem: Gemcitabine; 90Y: Yttrium-90; Oxa: Oxaliplatin; Pac: Paclitaxel; Sor: Sorafenib; TAE: Theoretical Additive Effect. The TAE column is the calculated product of cell viability following the two individual treatments. It reflects the value corresponding to a Combination Index of 1 (perfect addition). Value of the control is based on normalization. ${ }^{*}$ denotes $p<0.05$. 